\title{
Impact of MAGNET hospital designation on nursing culture: an integrative review
}

\author{
Vinah L. Anderson (1D ${ }^{\mathrm{a} *}$, Amy N.B. Johnston (10) ${ }^{\mathrm{b}, \mathrm{c}}$, Debbie Massey ${ }^{\mathrm{d}}$ and Anita Bamford-Wade \\ ${ }^{a}$ School of Health Sciences, University of Tasmania, Hobart, TAS 7000, Australia; ${ }^{b}$ Princess Alexandra \\ Hospital, Metro South, Woolloongabba, QLD 4102, Australia; ${ }^{c}$ The University of QLD, Translational \\ Research Institute, Woolloongabba, QLD 4102, Australia; ${ }^{d}$ School of Nursing, Midwifery and Paramedicine \\ University of the Sunshine Coast, Sippy Downs, QLD, 4558, Australia; ${ }^{e}$ Gold Coast University Hospital, E \\ Block, 1 Hospital Blvd, QLD 4215, Australia
}

(Received 25 September 2017; accepted 27 July 2018)

\begin{abstract}
Background: Organisational culture is a critical part of a positive and productive working environment and often presents as an area of ongoing development. The MAGNET recognition program awards recognition to organisations that have positive organisational cultures that meet the standards and criteria. However, the broad impact of MAGNET on hospital culture outside of America remains unclear.

Objective: In this study, we explore the impact of MAGNET designation on organisational culture within the nursing context.

Methods: An integrative literature review was performed using a systematic search of Medline (Ovid), Embase (Elsevier) and the Cumulative Index to Nursing and Allied Health Literature (CINAHL Ebsco) databases and a combination of subject headings and key words for organizational culture, organizational change and MAGNET hospital, as well as reference chaining was conducted. Using a constant comparative process key categories, themes and subthemes emerged.

Results: Twenty-nine key studies were identified and were evaluated utilising two study quality appraisal tools; National Health and Medical Research Council (NH\&MRC) levels of evidence and the Polit and Beck critical appraisal tool. Three key categories emerged from the data: (1) nurse practice environment; (2) structure and process models; (3) measurement scales. A key finding was that MAGNET designation appears to enhance organisational culture for nurses and the framework used to introduce MAGNET helps to empower nurses to direct organisational culture in their facility.

Conclusion and Implications for Nursing and Health Policy: MAGNET appears to have a positive impact on organisational culture, particularly for nurses. However, lack of standardised evaluation tools used to assess organisational culture associated with MAGNET designation limits comparability of the studies. Generally, the quality of evidence used to develop recommendations was poor to very poor. More, well designed studies undertaken outside of the USA are required.

Impact Statement: An in-depth integrative review exploring the impact of MAGNET designation on organisational culture has not been undertaken. In this paper, we have used an integrative review methodology to identify, examine, thematically group and critically evaluate published literature around the impact of MAGNET designation on organisational culture within designated hospitals.
\end{abstract}

\footnotetext{
*Corresponding author. Email: vinah.anderson@utas.edu.au
} 
Keywords: organizational culture; organizational change; MAGNET hospital; nursing; culture; MAGNET accreditation

\section{Background}

As health care undergoes redevelopment and reform, hospitals are faced with demographic, technological, financial and political challenges in delivering quality care within increasing budget constraints. To effectively address these issues managers of health care institutes are reassessing their 'organisational culture' to improve workplaces, reduce costs and, ultimately, enhance patient outcomes (Mannion, Davies, \& Marshall, 2005). In doing so, health care managers, planners and policy makers must consider increasing evidence pointing to the links between organisational characteristics, performance, quality indicators, and attributes of culture (Aiken \& Patrician, 2000; Aiken, Smith, \& Lake, 1994).

The success or failure of change processes and the translation of evidence into clinical practice within healthcare settings is hypothesised to be determined in part by organisational culture (Kutney-Lee, Stimpfel, Sloane, \& Cimiotti, 2015; Mäntynen et al., 2014). Empirically establishing the impacts of organisational culture on healthcare requires researchers to use clear and specifically defined terminology so that components and particularly changes in components, can be measured and observed. Tozer (1999, p.224) defines culture as

an environment shared and maintained by members of an organisation or social group; a way of life and set of beliefs and values that the elders wish the younger members to inherit and a major influence in the perception and behaviour of everyone living in that. (Tozer, 1999)

In this review, we use Tozer's definition to evaluate the relevance and impact of developing the MAGNET recognition program on organisational culture.

The MAGNET recognition program is a voluntary programme for hospitals who seek the highest international credentialing for nursing excellence and quality patient care through evidence-based practice (Bashaw, 2011; Basheaw, Rosenstein, \& Lounsbury, 2012; Drenkard, 2011). The overall aim of MAGNET recognition is to create a hospital culture that hospitals supports professional nursing care environments. Luzinski (2011) suggested that achieving MAGNET status often requires a fundamental shift in culture by a healthcare organisation so that the benefits of MAGNET extend beyond quality improvement and nurse practice development. Other areas dependent on organisational culture are, for example, improved safety, increased nurse engagement, satisfaction, and retention, better service and higher patient satisfaction, higher measurable financial return and improved patient outcomes (Aiken \& Patrician, 2000; Brady-Schwartz, 2005; Stone et al., 2007). These organisational improvements are embedded in the five amalgamated or synthesised 'magnetising' forces or components of MAGNET including: (1) transformational leadership; (2) structural empowerment; (3) exemplary professional practice and (4) new knowledge, innovations, and improvements and (5) empirical outcomes.

The MAGNET model components focus on transforming organisational culture through changes in structures, processes and outcomes that empower nurses to collectively engage in shared decision-making at all levels (George \& Lovering, 2013; Harris \& Cohn, 2014). Organisational culture associated with this model is based on values, attitudes, and beliefs about professional practice and the processes through which professional practice is supported in the workplace environment (Broom \& Tilbury, 2007).

Development of MAGNET based (enhanced) organisational culture, as noted above, often requires successful cultural change, that itself demands inter-professional and multi-level support within the organisation. Nurses, as the largest group of healthcare employees, are 
recognised as the key to mobilising efforts that enhance positive professional practice environments (Wooten \& Crane, 2003). Thus, the MAGNET framework focus on nurses and their roles, responsibilities and capacities, driven by and maintained by nursing staff, may be used by hospitals to achieve culture change at individual, unit and hospital management level to ensure eventual long-lasting effect to culture and organisational changes (Broom \& Tilbury, 2007; Drenkard, 2005).

Two systematic reviews conducted in 2009 and 2015 explored potential impacts of MAGNET designation. Salmond, Begley, Brennan, and Saimbert (2009) examined the impact of MAGNET designation on patient and nurse outcomes and found primarily positive outcomes of MAGNET designation on the professional practice environment. Salmond and colleagues also suggested that the evidence supported the investment in MAGNET and cited that MAGNET designation was associated with lower levels of emotional exhaustion, higher job satisfaction and higher intent to stay (Aiken \& Patrician, 2000; Schmalenberg \& Kramer, 2007; Stone et al., 2007). However, a more recent review by Petit Dit Dariel and Regnaux (2015, p. 198) concluded that:

while existing studies suggest that MAGNET designation, or the characteristics underpinning the MAGNET brand, offers an interesting opportunity to attract and retain staff and promote good practice, more rigorous designs are needed to establish causal links between the designation and outcomes.

Substantial investment and commitment is required of any organisation seeking MAGNET designation, yet the impact of MAGNET designation on measurable outcomes in changing or improving organisational culture remains unclear. The rationale for undertaking this integrative review and the research questions it addresses arose from the hospital executive teams' strategic plan to utilise the MAGNET designation process to help achieve the delivery of world-class health care (Gold Coast Health, 2016).

\section{Objective}

This review team will identify, examine, thematically group and critically evaluate published literature around the impact of MAGNET designation on organisational culture within designated hospitals. We will focus on identifying the impact of MAGNET designation on nursing staff and describe tools used to assess cultural change. Establishing best processes to explore organisational culture in hospitals undergoing MAGNET designation from within existing research was identified as a critical secondary aim.

The question this review aimed to answer was

1. Does the process of attaining MAGNET designation impact organisational culture for nurses and if so, how?

\section{Methods}

This integrative review was undertaken using a parallel, multi-stage process based on the model of Whittemore and Knafl (Whittemore \& Knafl, 2005) using two key authors to ensure unbiased application of key search, inclusion/exclusion and quality assessment strategies. The integrative review methodology and the use of Whittemore and Knafl's framework allowed the inclusion of literature from diverse methodologies in this case, quantitative, qualitative and descriptive designs, qualitative analysis, data synthesis and development of conclusions drawn from a variety of sources. All methodological studies were considered eligible for review. The exploratory nature of phenomena of interest determined the types of design published. 
Two quality appraisal tools were applied; the rigorous National Health \& Medical Research Council level of evidence tools (National Health and Medical Research Council, 2009) and the Polit-O'Hara and Beck quality appraisal tool, a tool designed to encompass the wide range of study designs used in nursing and management research (Polit-O'Hara \& Beck, 2006). Both tools were applied independently by two reviewers after the application of systematic inclusion and exclusion criteria. A third reviewer was available if any differences arose from the selection process. Differences in rating were resolved by consensus discussion between the two identified reviewers.

\section{Inclusion/exclusion criteria}

Only MAGNET hospitals in the process of designation and first-time MAGNET hospitals were included. Studies were excluded if the article was unclear or did not state MAGNET status, and if the hospital was seeking to or had achieved MAGNET redesignation. Participants in hospitals that utilised the MAGNET framework to address organizational change but did not undertake the official American Nurses Credentialing Centre credentialing programme were also excluded from the review.

\section{Search strategy}

The search strategies, including databases accessed, are represented in Figure 1. With the assistance of an experienced library technician a comprehensive search strategy was undertaken in two stages. Stage one included the initial search of the literature in Medline, CINAHL \& Google scholar to identify and refine the search terms for the final search. The key words used in this search were; organization, culture, MAGNET and nursing. The more complex search included the words: organization* or organisation*, "Organizational Development", "Organizational Culture+", "Magnet Hospital Accreditation", and "Magnet Hospitals".

There was no restriction to year of publication. The Joanna Briggs database for Systematic reviews was also searched to prevent repetition of the review process. The second stage, undertaken by the library technician on the 19th May 2016, included searches via Embase, CINAHL and Medline (Ovid) databases and is reported in Table 1. Activation of 'smart text' and automatic word variation options during searches ensured that word combination options including American and British spelling variations and plural terms were detected. Reference chaining was undertaken. All final (hand) searches were conducted in June 2016.

\section{Data analysis}

Analysis using a constant comparative method that included data reduction, data display, data comparison, conclusion drawing, and verification (Miles \& Huberman, 1994) enabled the creation of categories and subthemes from the included research studies.

\section{Results}

\section{Design and quality}

Twenty-nine studies were reviewed and quality appraised. Twenty-one studies used quantitative methodology, six used qualitative and two used mixed methods methodology. Twenty-five of the 29 papers (86\%) appraised were conducted in America; one in Australia; one in Finland; one in Saudi Arabia and one in the United Kingdom. All 29 studies appraised using the NH\&MRC and Polit-O'Hara and Beck criteria proved to be of poor quality with 25 studies producing scores of 


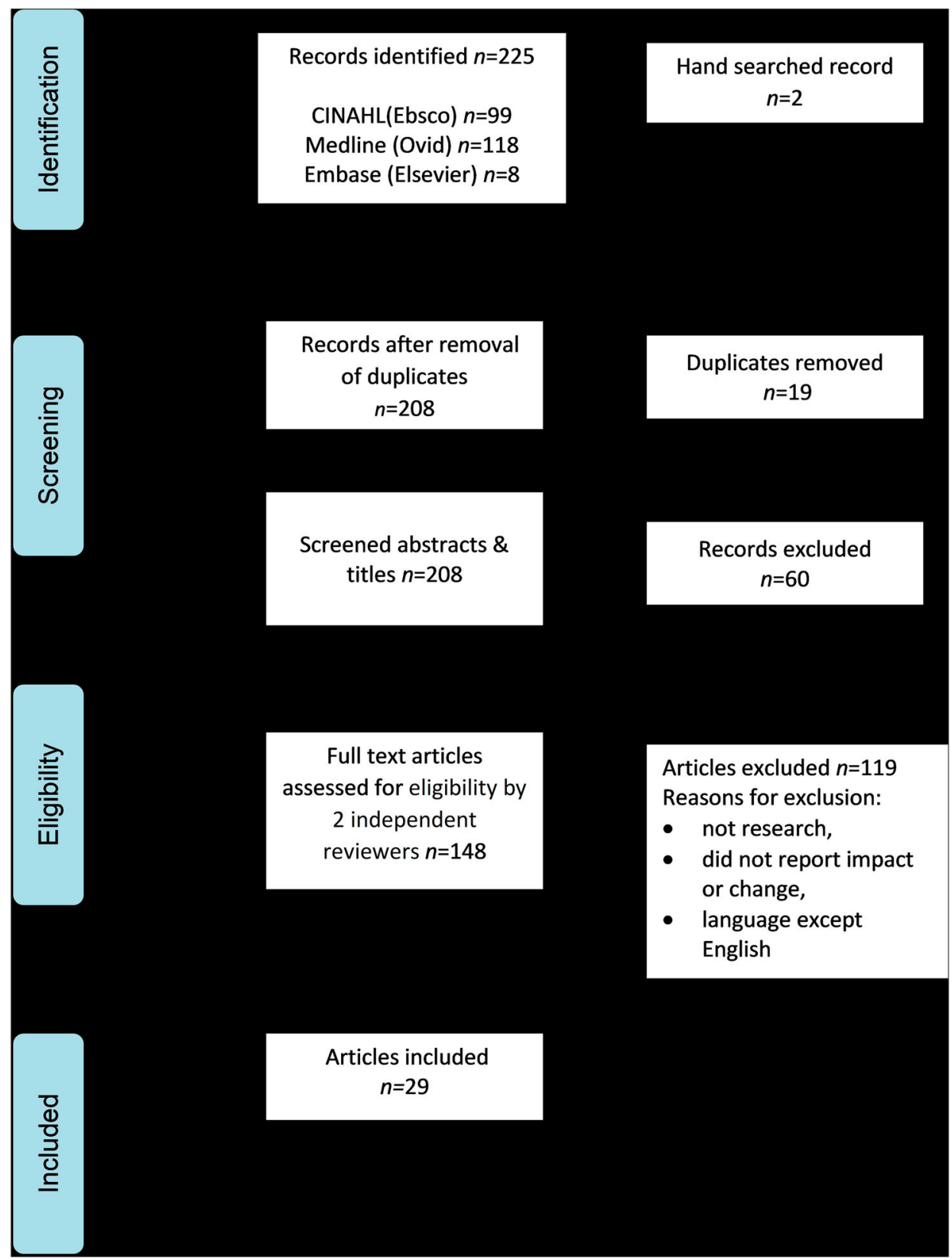

Figure 1. Flow diagram of study selection for inclusion in this review, based on PRISMA guidelines (Moher, Liberati, Tetzlaff, Altman, \& Group, 2010).

IV/VI levels of evidence respectively. Two studies (Havens, 2001; Hess, Desroches, Donelan, Norman, \& Buerhaus, 2011) had scores of III-3/VI and the remaining two studies (Aiken \& Patrician, 2000; Kutney-Lee et al., 2015) scored III-3/IV. Fourteen out of 29 studies did not report formal ethics approval to undertake the study (Table 2). Critically, no clear definitions of 'organisational culture' were provided in any of the studies, however apparent attributes of 
Table 1. Search strategy.

\begin{tabular}{llr}
\hline Search ID\# & \multicolumn{1}{c}{ Database CINAHL } & Results \\
\hline S11 & S4 AND S9 Limiters applied - (Exclude MEDLINE records) & 99 \\
S10 & S4 AND S9 & 279 \\
S9 & S5 OR S6 OR S7 OR S8 & 30,314 \\
S8 & TI ((organization* or organisation*) N2 cultur*) OR AB & 1,996 \\
S7 & ((organization* or organisation*) N2 cultur*) & \\
S6 & (MH "Organizational Development+") & 8,656 \\
S5 & (MH "Organizational Change") & 9,431 \\
S4 & (MH "Organizational Culture+") & 14,061 \\
S3 & S1 OR S2 OR S3 & 2,309 \\
S2 & TI magnet N3 hospital* OR AB magnet N3 hospital* \\
S1 & (MH "Magnet Hospital Accreditation") & 605 \\
Embase & (MH "Magnet Hospitals") & 57 \\
$\# 5$ & & 2,136 \\
$\# 4$ & \#3 AND \#4 & \\
$\# 3$ & ((organisation* OR organization*) NEAR/3 cultur*):ab,ti & 8 \\
$\# 4$ & \#1 OR \#2 & 3320 \\
$\# 1$ & (magnet NEAR/3 (hospital* OR model OR status)):ab,ti & 473 \\
Medline Ovid & 'magnet hospital'/de & 472 \\
1 & & 25 \\
2 & (magnet adj4 (hospital* or model or status)).tw. & \\
3 & organizational culture/ & 511 \\
4 & ((organization* or organisation*) adj4 cultur*).tw. & 14305 \\
5 & 2 or 3 & 3427 \\
\hline
\end{tabular}

organisational culture within the nursing context during the MAGNET designation process were reported.

The three main categories identified in this review were (1) the nurse practice environment, (2) shared governance models and (3) the measurement scales/tools.

\section{Nurse practice environment}

MAGNET designation processes exploring and supporting information about nurses' perceptions of their professional role within the practice environment including autonomy, decision-making, and organizational support were examined in eight studies (Force, 2004; George \& Lovering, 2013; Hess et al., 2011; Kutney-Lee et al., 2015; Lacey et al., 2007; Mäntynen et al., 2014; Shepherd, Harris, Chung, \& Himes, 2014; Walker, Fitzgerald, \& Duff, 2014). Organisational culture and the impact this has on physician and nurses' professional relationship was examined in five studies (Aiken \& Patrician, 2000; Gerhardt \& VanKuiken, 2008; Hess et al., 2011; Ulrich, Buerhaus, Donelan, Norman, \& Dittus, 2007; Walker et al., 2014).

\section{Shared governance model}

MAGNET designation requires hospitals/organisations to review current structure and processes and demonstrate the use of a model that leads to greater nurse empowerment and autonomy. A shared governance model was identified as important in 8 studies (Balogh \& Cook, 2006; Force, 2004; George \& Lovering, 2013; Harris \& Cohn, 2014; Hession-Laband \& Mantell, 2011; King, 2011; Lewis, 2009; Upenieks \& Abelew, 2006). A shared governance model was 
Table 2. Study characteristics.

\begin{tabular}{|c|c|c|c|c|}
\hline $\begin{array}{l}\text { Author, year, } \\
\text { journal, country }\end{array}$ & Aims/objective & Design/methods, analysis & Sample size, participants, site & Findings \\
\hline $\begin{array}{l}\text { Warren et al., 2016, } \\
\text { Worldviews on } \\
\text { evidence-based } \\
\text { nursing, USA }\end{array}$ & $\begin{array}{l}\text { To evaluate the strength of and } \\
\text { the opportunities for } \\
\text { implementing evidence-based } \\
\text { nursing practice } \\
\text { To describe RNs attitudes, } \\
\text { beliefs, and perceptions about } \\
\text { readiness and implementation } \\
\text { of EBP in a multihospital } \\
\text { healthcare system. }\end{array}$ & $\begin{array}{l}\text { Quantitative - cross sectional } \\
\text { surveys } \\
\text { Surveys conducted from May } \\
2012 \text { to July } 2012 . \\
\text { Data analysis- } \\
\text { ANOVA and Levene's test for } \\
\text { homogeneity of variance, and } \\
\text { Tukey HSD test for post hoc } \\
\text { comparisons. } \\
\text { The Welch ANOVA and } \\
\text { Games-Howell post hoc. }\end{array}$ & $\begin{array}{l}\text { Convenience sample }-6,800 \\
\text { nurses employed by a mid- } \\
\text { Atlantic healthcare system. } \\
\text { Not-for-profit healthcare } \\
\text { system, } \\
7 \text { hospitals in Maryland and } \\
3 \text { in the District of } \\
\text { Columbia. } 9 \text { hospitals at the } \\
\text { time of the study. }\end{array}$ & $\begin{array}{l}\text { RNs in MAGNET designated } \\
\text { hospitals reported more } \\
\text { resources and positive } \\
\text { perceptions toward their } \\
\text { hospital's organizational } \\
\text { readiness and system-wide } \\
\text { integration of EBP compared to } \\
\text { non-Magnet hospital RNs. }\end{array}$ \\
\hline $\begin{array}{l}\text { Kutney-Lee et al., } \\
\text { 2015, Medical } \\
\text { Care, USA }\end{array}$ & $\begin{array}{l}\text { To compare changes over time } \\
\text { in surgical patient outcomes, } \\
\text { nurse-reported quality, and } \\
\text { nurse outcomes in a sample of } \\
\text { hospitals that attained } \\
\text { MAGNET recognition } \\
\text { between } 1999 \text { and } 2007 \text { with } \\
\text { hospitals that remained non- } \\
\text { MAGNET. }\end{array}$ & $\begin{array}{l}\text { Quantitative Retrospective, } 2- \\
\text { stage panel design. } \\
\text { Identical Nursing surveys } \\
\text { conducted in } 1999 \text { \& } 2006 \\
\text { Data collected by the Centre for } \\
\text { Health Outcomes \& Policy } \\
\text { Research at the university. } \\
\text { Descriptive statistics. Fixed- } \\
\text { effects difference models. }\end{array}$ & $\begin{array}{l}\text { All actively licenced RNs. } \\
\text { Surgical patients. } \\
\text { MAGNET } n=11 \text { \& Non- } \\
\text { MAGNET } n=125 \text {. } \\
\text { RN's randomly selected } \\
\text { from states. Surveys mailed } \\
\text { out. }\end{array}$ & $\begin{array}{l}\text { Emerging MAGNET hospitals had } \\
\text { greater improvements in } 30 \text {-day } \\
\text { surgical mortality and failure to } \\
\text { rescue rates compared to non- } \\
\text { MAGNET. }\end{array}$ \\
\hline
\end{tabular}


Table 2. Continued.

\section{Author, year, \\ journal, country}

Kaplan et al., 2014,

Journal for

Nurses in

Professional

Development,

USA

Shepherd et al.,

2014, Journal of

Nursing

Education \&

Practice, USA
Aims/objective

To evaluate whether

organizational culture for

EBP of a MAGNET hospital

was affected by a hospital-

wide project to increase the

EBP knowledge and skills of

nurses.
This article describes strategies, such as the Aware Desire Knowledge Ability

Reinforcement Model used, to build a shared governance culture to prepare bedside

clinicians to own their practice and patient outcomes.
Design/methods, analysis

Quantitative. Quasi-experimental. Sample - all nurses at a 300-

Pre-survey - Time 1 (T1)

between Oct 15 \& Oct 312012.

Post survey - Time 2 (T2)

between May 13 \& May 27

2013.

Intervention occurred between

Nov 12012 \& May 102013.

Intervention-

Phase 1 - All nurses received

an electronic newsletter

'Evidence Based Practice

Pearls' every 2 weeks. Phase 2

- cohort of primarily direct care

nurses who participated in a

series of EBP workshops on

development, implementation

$\&$ dissemination of an EBP

project.

Data analysis:

Pearson mean. Pearson $\mathrm{r}$

correlations.

ANOVA.

Descriptive - quantitative

Descriptive survey data.

Time period -commenced early 2000 (pre-

implementation), 2004 (early

implementation), 2012

(Implemented)
Sample size, participants, site

bed Magnet hospital.

$n=943$ nurses employed

pre-intervention $\& n=939$

employed post- intervention

survey.

An electronic email with a

link to an online survey was

sent to all nurses at the

hospital.

1 hospital

Survey sample size- baseline survey distributed

electronically to 1119 nurses
Intervention increased nurses'

confidence in a MAGNET

hospital in EBP environment. 
Urden et al., 2013,

The Journal of Nursing Admin, USA

Hess et al., 2011, Journal of

Nursing Admin, USA

Hession-Laband and Mantell,

2011, Journal of Pediatric

Nursing, USA
To compile a rich description of the phenomenon of MAGNET journey by registered nurses in clinical settings who provide direct patient care in community healthcare systems recently receiving MAGNET designation.

To compare perceptions of $\mathrm{RNs}$ employed in MAGNET, inprocess (i.e. hospitals seeking MAGNET recognition), \& non-MAGNET hospitals using data from the 2010 National Survey of Registered Nurses (NSRN).

To describe a process by which nurses at the Children's

Hospital Boston worked to increase error reporting and used the knowledge gained from these reports to implement practice changes leading to improvements in safety and quality.
Iterative organisational

process, line by line analysis using codes \& categories resulting in emerging themes.

Quantitative design - survey

Bivariate analysis.

Survey conducted from May to August 2010

Focus groups 8 in total. 3 at the community hospital and 5 at the health system.

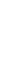

Descriptive - comparative survey study - quantitative results

Intervention post-2008 survey included education \& training sessions on the systems functions, importance of reporting near misses, benefits of reporting \& examples of change.

Data analysis not described.

Results described as

percentages.

2008 \& 2010 survey data compared.
Setting-1 community hospital $\& 1$ district healthcare system in southwest USA recently received ANCC MAGNET designation. Sample: $n=58$ nurses

\section{Random sample $-n=1500$ \\ RNs. Sample drawn from a national database.}

\section{Themes}

Relationships with leaders;

MAGNET continuum;

Professional relationships;

Professional development; Staff

voice; Resources/support

Professional accountability;

MAGNET slippage;

Recommendations from nurses.

Last 3 surveys, nurses in

\section{MAGNET}

facilities reported consistently high satisfaction with being a nurse. Nurses at in-process

facilities trended upward.

MAGNET nurses reported more musculoskeletal injuries.

Opportunities to influence decisions and participate in shared governance were rated higher in MAGNET nurses and in-process MAGNET.

Site - 396-bed pediatric health care.

Sample in $2008-n=675$ direct care nurses in general medical \& surgical units \& emergency dept. $2010-n=256$ direct care nurses in general medical \& surgical units
The medical and surgical units experienced a $35 \%$ increase in reported events over the 2-year period.

Safer systems; computerised order entry, computerised medication administration record, and bar coding. $63 \%$ increase in reporting of VAD- related events in medical \& surgical units. Various practice changes included rounding, staff education targeting assessment skills, infiltration and extravasation risk factors, use of securement of devices and partnering with parents. 


\section{Author, year, \\ journal, country}

King, 2011,

American Society

of Radiologic

Technologists

Scanner, USA
The author's description of transforming the medical imaging department's culture in seeking MAGNET designation.
Jost and Rich, 2010, Experience of one hospital's

Nursing Admin

Quarterly, USA

journey to MAGNET

designation.
The article identifies the link that was required to transform the nursing division culture to achieve MAGNET.
Trinkoff et al., 2010, To compare working conditions Journal of Nursing Admin USA of nurses working in

American Nurses

Credentialing Center designated MAGNET and non-MAGNET hospitals.

\section{Descriptive}

Time period - Magnet was approx 5 years.

Cross-sectional comparative

\section{design}

Quantitative

Baseline cohort of which

$82.4 \%(n=2,156)$ participated

in the third wave of data

collection used in this analysis.

$t$-tests, (age) \& Pearson x2

(sex) \& Fisher exact tests.

Bivariate analyses.

Huber-White sandwich

estimator of variance -

clustering of nurses in a

hospital.
One 704-bed tertiary, academic medical centre. Nursing division $=$ approx. 1700

RN's, $>85 \%$ hold a BSN or

higher.

Physicians were also

involved.

Sample $n=837$ active licensed nurses working in 171 acutecare non-federal, general medical-surgical hospitals. Hospitals were designated as MAGNET $(n=14)$ or not $(n=157)$ based on 2005 American Nurses

Credentialing Center accreditation status.

Transformed from just getting

the 'exam' done to a better mission and vision.

Multi-components identified: Respectful workplace, skilled communication, authentic leadership, shared governance, partnerships, evidence-based practice, and integrated care reflected world-class patient care.

Ownership of the model had occurred which signalled a key moment of crystallization that unified isolated events into a significant trend.

MAGNET nurses less likely to report their jobs contained mandatory overtime than nonMAGNET nurse. Physical demands were lower among MAGNET hospitals nurses versus those working in nonMAGNET hospitals.

Nursing practice environment (NWI-R), patient safety culture, and overall job satisfaction - no significant differences between groups. 
Lewis, 2009, Nurse Leader, USA

Focus is on the Chief Nursing Officer's role in the development \& sustainability of one mission critical component-organizational culture.

Newcomb et al., 2009, Southern Online Journal of Nursing

Research, USA 2008, Journal of

Nursing Care \& Quality, USA

Gerhardt and VanKuiken, 2008, The Journal of Nursing Admin, USA

To determine whether there was evidence of change in nurse satisfaction when a nursing practice model was changed as part of an organization's effort to achieve MAGNET characteristics.

To identify the barriers and facilitators of research utilization in a community hospital.

To assess the "readiness" of this organisation's work environment for MAGNET application by comparing organisation results with

published findings of
Quantitative. A narrative.

Time period 1998-2008.

Data monitored over a 10 year period from NDNQI databases benchmarked against other hospitals.

MAGNET and non-

MAGNET organisations.

Quantitative. Cross-sectional study 2004 to 2006

Data analysis - descriptive statistics, repeated measures ANOVA, regression analysis, chi-square

Descriptive quantitative design. Timeframe for questionnaire $=$ 6 weeks. 2002-2006.

Descriptive statistics.

Additional barriers to research utilisation included themes.

Descriptive quantitative design Descriptive statistics - 1sample t tests. 2-sample t test. days.
Nursing and in-patients.

In-patient satisfaction increased.

Overall job satisfaction

remained high.

Nursing turnover reduced to zero, improved sense of

camaraderie, improved self-care, increased use of stress

management skills learned.

282-bed tertiary care paediatric hospital

All 800-848 paediatric

licensed bedside nurses (yrs 2004-2006).

Non-random sample Survey was available for 31
Most satisfying: Professional status; interaction and autonomy. Most unsatisfying: Pay Task requirements:

Nurses' satisfaction increased on

Organizational policies: Nurses were dissatisfied with scheduling control and hospital administration.

Themes: Majority of the barriers $(52 \%)$ were related to lack of time to read, discuss, implement, or evaluate research.

Organizational scores - higher than scores from non-MAGNET hospitals. No differences on collaboration. Control over practice score was greater than scores in known MAGNET hospitals. clerical and paper work. autonomy and RN-MD
All RNs working across a variety of settings in a community-based hospital. Hospital was undergoing MAGNET journey.

A paediatric medical centre 475 beds \& 36 psychiatric residential beds.

Sample - all nurses, RN's, \& APN's employed in direct patient care.

Survey was distributed electronically via email by the researchers. 
Table 2. Continued.

\begin{tabular}{|c|c|c|c|c|}
\hline $\begin{array}{l}\text { Author, year, } \\
\text { journal, country }\end{array}$ & Aims/objective & Design/methods, analysis & Sample size, participants, site & Findings \\
\hline $\begin{array}{l}\text { Lacey et al., } 2007 \text {, } \\
\text { The Journal of } \\
\text { Nursing Admin, } \\
\text { USA }\end{array}$ & $\begin{array}{l}\text { To determine differences in } \\
\text { registered nurses' perceptions } \\
\text { of manager, peer, unit } \\
\text { support, workload, intent to } \\
\text { stay, and satisfaction between } \\
3 \text { types of institutions: } \\
\text { MAGNET, MAGNET- } \\
\text { aspiring, and non-MAGNET. }\end{array}$ & $\begin{array}{l}\text { Quantitative - secondary analysis } \\
\text { Survey data - January } 2003 \text { - } \\
\text { June } 2005 \text {. } \\
\text { Descriptive statistics, ANOVA, } \\
\text { Tukey post hoc test used for } \\
\text { comparisons. }\end{array}$ & $\begin{array}{l}15 \text { institutions: } 2 \text { MAGNET, } \\
10 \text { MAGNET }- \text { aspiring, } \\
\text { and } 3 \text { non-MAGNET sites. } \\
\text { Bed size }- \text { ranged from }<200 \\
\text { to }>500 \text { beds. } \\
\text { Staff nurses. Child Health } \\
\text { Corporation of America } \\
\text { assisted in the recruitment of } \\
\text { facilities. }\end{array}$ & $\begin{array}{l}\text { Nurses in MAGNET recognized } \\
\text { hospitals have more positive } \\
\text { perceptions of support for nurses } \\
\text { than nurses in either MAGNET- } \\
\text { aspiring or non-MAGNET. }\end{array}$ \\
\hline $\begin{array}{l}\text { Ulrich et al., 2007, } \\
\text { The Journal of } \\
\text { Nursing Admin, } \\
\text { USA }\end{array}$ & $\begin{array}{l}\text { To compare how registered } \\
\text { nurses view the work } \\
\text { environment and the nursing } \\
\text { shortage based on the } \\
\text { MAGNET status of their } \\
\text { organisations. }\end{array}$ & $\begin{array}{l}\text { Descriptive quantitative survey } \\
\text { design } \\
\text { Descriptive statistics }-t \text { tests. }\end{array}$ & $\begin{array}{l}\text { Random sample of nurses from } \\
\text { currently licensed RNs in the } \\
\text { US. } \\
\text { Final sample }=1,783 \\
\text { completed surveys }\end{array}$ & $\begin{array}{l}\text { Identifiable differences of nurses } \\
\text { perception of their work } \\
\text { environments between } \\
\text { MAGNET, aspiring-MAGNET } \\
\text { and non-MAGNET hospitals. }\end{array}$ \\
\hline $\begin{array}{l}\text { Upenieks and } \\
\text { Abelew, 2006, } \\
\text { The Health Care } \\
\text { Manager, USA }\end{array}$ & $\begin{array}{l}\text { 1. What structures were } \\
\text { implemented to achieve } 14 \\
\text { forces of magnetism? } \\
\text { 2. To compare results with } \\
\text { baseline data obtained in } 2009 \\
\& 2003 \text { ) to benchmark results } \\
\text { with data from other } \\
\text { MAGNET organizations. }\end{array}$ & $\begin{array}{l}\text { A qualitative descriptive design } \\
\text { Tape recorded Interviews - } 30- \\
90 \text { minutes. } \\
\text { Content analysis. } \\
\text { Comparative analysis between } \\
\text { hospitals. } \\
\text { Practice Environment scale } \\
\text { administered in Sept/Oct } 2012 \text {. }\end{array}$ & $\begin{array}{l}\text { Convenience sample } 2 \\
\text { hospitals. } 1 \text { hospital=> 500- } \\
\text { bed medical centre, } 1 \\
\text { hospital }=300 \text {-bed } \\
\text { community hospital. } \\
\text { Purposive sampling. } \\
\text { Sample population }=n=12 \\
\text { nurse leaders; } n=12 \\
\text { registered nurses from } 2 \\
\text { hospitals ( } 6 \text { nurses \& } 6 \\
\text { leaders from each } \\
\text { institution) }\end{array}$ & $\begin{array}{l}\text { Themes: Structural factors } \\
\text { Process factors } \\
\text { Key structural factors: } \\
\text { Technology-staff expressed the } \\
\text { importance of having right } \\
\text { equipment to do their job. } \\
\text { Key Process factors } \\
\text { Patient centeredness - } \\
\text { emphasized the importance of } \\
\text { engaging pts in the delivery } \\
\text { process. Mentorship programs - } \\
\text { implementation of a clinical } \\
\text { mentorship program. }\end{array}$ \\
\hline
\end{tabular}

MAGNET, MAGNET-

compare how registered nurses view the work shortage based on the MAGNET status of their

Abelew, 2006,

The Health Care ith data from other

Practice Environment scale hospitals ( 6 nurses \& 6 leaders from each mentorship program. 
Capuano et al., 2005, Health

Care

Management

Review, USA
Cimiotti et al., 2005, To compare the differences Nursing Research, USA

Force, 2004, The Health Care Manager, USA

MAGNET hospitals, process MAGNET

certification, and non-

environment.

The paper described their change by following the
To evaluate the work

environment for nurses at

LVHHN and to use an applied

research study to identify

changes that would improve effectiveness
Applied research project.

Quantitative \& qualitative data.

Evaluation of an existing

structural equation model. Path

coefficients from LVHHN.

One-sample $t$-tests with

Bonferroni adjustments to analysis of variance

(MANOVA) for scale scores.

Linear regression Wilks'

lambda method.

Cross-sectional survey design, quantitative Chi-square, multivariate analyses. Data collected between Oct 2002 \& April 2003.

MAGNET hospitals, and how nurses from these hospitals

perceive their work journey in creating a culture

MAGNET recognition

program for Nursing

Excellence using the Shared

Governance Councillor

Model

Quantitative. Descriptive/ alpha. ANOVA, multivariate general linear model, \&

Nursing Database sample size $n=105$ patient care units in a large teaching facility. Model was applied to 34 units as an evaluation tool. Directors \& division administrators including subordinates (observers)

Nurses - 2,323 responses (Final sample $=2,092) 110$ ICUs in 68 hospitals. discussion paper 1998-2003

Staff, physicians \& leaders. Nursing practice subcommittee 1998-2000 Shared decision-making 2000-2003 5 central councils -2 nurse leaders \& staff nurses representing every nursing unit in the hospital.
Leadership: LVHHN had strongest internal leadership scores on the scales of 'enabling' and 'inspiring' compared to other hospitals. Work environment for LVHHN was rated higher than national norms on involvement, autonomy, task orientation, innovation, \& physical comfort.

Perception of workload Had significantly higher scores on perceptions of workload than national norms/database sample.

Work environment Nurse-

physician collaboration scores were similar across all hospitals. On average, nurses working in in-process MAGNET hospitals had lower mean scores on nurse management, staffing and resource adequacy, professional practice nursing, nursing competence and positive scheduling climate compared to nurses from MAGNET and nonMAGNET hospitals

Nurse turnover rate decreased.

Enhanced clinical practice and increased staff moral and nurse retention. Increased staff

satisfaction, nurse satisfaction, confidence, leadership skills \& self-esteem in staff nurses. Integration of new roles, skills, and behaviours. 
Table 2. Continued.

Author, year,

journal, country

(2)

Havens, 2001,

Nursing

Economics, USA

To explore potential differences in the infrastructures

supporting nursing practice in

2 groups of hospitals.

Aiken and Patrician, 2000, American

Journal of

Nursing, USA
To examine whether ANCCrecognized MAGNET hospitals had the same organizational attributes responsible for excellent nursing care as the original MAGNET hospitals did and whether they had high rates of nurse satisfaction and the same quality of care (as assessed by nurses).
Quantitative. Comparative multisite observational study design - two subsamples of hospitals. Descriptive statistics using $t$-tests $\&$ bivariate

analyses. Study undertaken in Spring 1998
Sample size, participants, site

Findings

Chief nursing executives $n=$

21 Comparison hospital

(original Magnet) $n=24$,

ANCC MAGNET hospitals $n=19$.

Medical-surgical nurses at all institutions. ANCC

MAGNET hospital, $n=7$.

Original MAGNET, $n=13$ ANCC group.

Identifiable differences between

the 2 groups: ANCC group had higher JCAHO scores. CNEs of ANCC group appraised the quality of care higher than Original group. Differences in organizational structures of nursing. Organizational support for nurses was higher for ANCC group. Restructuring and work design activities were lower in

Education ANCC nurses had less nursing experience, fewer years of employment, and fewer years assigned in current units, than original MAGNET nurses.

Nurse staffing: Higher RN to patient ration in ANCC group. Clinical practice environment: Nurse autonomy and nurse control were higher in ANCC group. Nurses more likely to report their units have adequate support services, adequate time to discuss patient problems, control their own practice, participate in policy decisions, have powerful chief nursing executives. 
Walker et al., 2014, The Journal of Nursing Admin, Australia

\section{Mäntynen et al., 2014, Nursing Research \&}

Practice, Finland

\section{George and}

Lovering, 2013, Nursing Admin

Quart, Saudi Arabia
To assess clinical nurses' perceptions of the Practice Environment at one hospital.

Describes the changes in transformational leadership and quality outcomes that occurred between 2008 and 2011 in a Finnish university hospital that is aiming to meet the Magnet standard.

To explore the concept of the Chief Nursing Officer's role of transforming the culture \& context of nursing through the establishment of shared leadership \& partnership principles.
Quantitative. Comparative study. Practice Environment scale administered in Sept/Oct 2012.

\section{ENs, \& AINs 13 clinical units.}

Longitudinal study - descriptive $\&$ quantitative aspects.

Baseline survey data collected 2008-2009 Follow-up data were gathered in 2010-2011 Survey - transformational leadership, job satisfaction, patient Exploratory factor analysis, reliability analysis (Cronbach's $\alpha$ ), and nonparametric (MannWhitney)

Quantitative. A case study. Commenced the journey to MAGNET in 2005. Used National Database Nursing Quality Indicator RN satisfaction survey data for years 2009-2012 to demonstrate cultural change within the nursing context.

Setting - university hospital 770 beds \& approx. 2700 nursing staff. Sample nurses, nursing leaders, patients. Random sample.

\section{Nursing staff (roles not defined)}

Mean scores on all subscale were higher than MAGNET hospitals in United States except for "staffing and resource adequacy," and "nursing unit manager ability, leadership, and support of nurses," was not significant. Mean scores were higher than Australian nonMAGNET.

Job satisfaction scores increased. Transformational leadership scores remained below target. Patient safety culture scores increased.

RN satisfaction was higher than
non-MAGNET \& MAGNET.
Nursing turnover decreased by
nearly half since implementation
of Professional practice model.
Majority of the nurse sensitive
outcomes achieved better than
the benchmark results for $2010-$
2011. 
Table 2. Continued.

\begin{tabular}{|c|c|c|c|c|}
\hline $\begin{array}{l}\text { Author, year, } \\
\text { journal, country }\end{array}$ & Aims/objective & Design/methods, analysis & Sample size, participants, site & Findings \\
\hline $\begin{array}{l}\text { Balogh and Cook, } \\
\text { 2006, Journal of } \\
\text { Nursing } \\
\text { Management, UK }\end{array}$ & $\begin{array}{l}\text { Explored the MAGNET } \\
\text { designation process in the first } \\
\text { health care Organization } \\
\text { outside the USA to attempt to } \\
\text { gain the award, Rochdale } \\
\text { NHS Trust United Kingdom. }\end{array}$ & $\begin{array}{l}\text { Case study - qualitative Data } \\
\text { analysis - Early data were } \\
\text { initially coded for emergent } \\
\text { issues. Progressive focusing } \\
\text { technique used as per Stake's } \\
\text { framework. MAGNET journey } \\
\text { 2000-2002. }\end{array}$ & $\begin{array}{l}\text { A healthcare NHS Trust. A } \\
\text { purposive sample }-n=11 \\
\text { senior staff members - } \\
\text { managerial, medical, nursing } \\
\text { and non-Executive Board } \\
\text { members, and other senior } \\
\text { staff involved in } \\
\text { implementing the MAGNET } \\
\text { project including an allied } \\
\text { health professional. }\end{array}$ & $\begin{array}{l}\text { Emergent themes The Experience } \\
\text { Strategy for achieving } \\
\text { MAGNET Preparation } \\
\text { Initiatives Nursing director } \\
\text { noted increased levels of } \\
\text { enthusiasm among medical } \\
\text { colleagues. }\end{array}$ \\
\hline
\end{tabular}

Notes: EBP, Evidence-Based Practice; RNs, Registered Nurses; OCRSIEP, Organizational Culture Readiness for System-wide Integration; EBPI, Evidence-Based Practice

Implementation; APRNs, Advanced Practice Registered Nurses; PES-NWI, Practice Environment Scale-Nurse Working Indicator; NDNQI, National Database of Nursing Quality Indicators; T1, time point 1; T2, time point 2; BSN, Bachelor Science in Nursing; yr, year; ANCC, American Nurses Credentialing Center; USA, United States of America; Dept, department; VAD, Vascular Access Device; NWI-R, Nursing Work Index Revised; MD, Medical Doctor; IWPS, Individual Workload Perception Scale; mths, months, LVHHN, Lehigh Valley Hospital \& Health Network; ICU, Intensive Care Unit; CNE, Chief Nurse Executive; ENs, Enrolled Nurses; AINs, Assistant in Nursing; JCAHO, Joint Commission: Accreditation Health Care Certificatioin; NHS, National Health Service; UK, United Kingdom. 
identified as enabling and facilitating the transformation of nursing culture from a hierarchical to a more flattened structure. Improved quality of care and increased job satisfaction was identified at an outcome of shared governance (Force, 2004; George \& Lovering, 2013; Hession-Laband \& Mantell, 2011; Jost \& Rich, 2010; Kaplan, Zeller, Damitio, Culbert, \& Bayley, 2014; Lewis, 2009; Shepherd et al., 2014; Warren et al., 2016).

\section{Measurement scales}

Measurement scales designed to assess components of organisational culture were varied, some were developed informally by the hospital or the researcher (Table 3) (Force, 2004; Havens, 2001; Hess et al., 2011; Hession-Laband \& Mantell, 2011; Lewis, 2009; Shepherd et al., 2014; Urden, Ecoff, Baclig, \& Gerber, 2013). In comparison, other measurement scales were subjected to rigorous reliability and validity testing (Aiken \& Patrician, 2000; Atkinson, Turkel, \& Cashy, 2008; Capuano, Bokovoy, Hitchings, \& Houser, 2005; Cimiotti et al., 2005; Gerhardt \& VanKuiken, 2008; Harris \& Cohn, 2014; Kaplan et al., 2014; Kutney-Lee et al., 2015; Lacey et al., 2007; Newcomb, Smith, \& Webb, 2009; Trinkoff et al., 2010; Warren et al., 2016).

\section{Discussion}

Evidence from this integrative review suggests MAGNET has a positive impact on nurses' perceptions of their professional role including autonomy, decision-making, and leadership, implying that MAGNET has a real and positive impact on organisational culture especially from a nursing perspective. This is the first integrative review to explore the impact of Magnet of the five amalgamated or synthesised forces or components: (1) transformational leadership; (2) structural empowerment; (3) exemplary professional practice and (4) new knowledge, innovations, and improvements and (5) empirical outcomes on organisational culture. It is also the first time a clear definition of culture has been explored within the MAGNET framework, thus making an important contribution to knowledge and understanding of the enhancement of organisational culture associated with MAGNET designation.

Twenty-nine studies addressed the key inclusion/exclusion criteria including data from nonAmerican sites. Three key categories emerged from the data: (1) nurse practice environment; (2) shared governance models; and (3) measurement scales.

A common focus of MAGNET-related research is the professional practice environment, particularly of nurses. According to the American Nursing Credentialing Centre, a requirement of the MAGNET designation is demonstrated evidence of improvement in the practice environment. Improving the practice environment is thought to have a positive effect on both nurse and patient satisfaction levels and quality of care (Aiken et al., 1994; Scott, Sochalski, \& Aiken, 1999). Assessment of the practice environment around MAGNET designation also demonstrated enhanced retention, recruitment, workload, and reduced burnout reflective of a sustained improvement in the organisation's culture (Aiken \& Patrician, 2000; Harris \& Cohn, 2014; Kutney-Lee et al., 2015; Lacey et al., 2007; Ulrich et al., 2007).

Culture is dependent on nurses' feelings of autonomy and nurse's autonomy is dependent on governance models (Force, 2004; Gerhardt \& VanKuiken, 2008; Shepherd et al., 2014). The shared governance model is the core of the MAGNET and embodies the concepts of partnership, equity, accountability and ownership (Shepherd et al., 2014). The shared governance model offers the opportunity for nurses to participate in the decision-making process at every level of the organisation (Porter-O'Grady, 1991). According to Porter-O'Grady, applying these principles enables the development of interdisciplinary relationships across the organisation leading to 
Table 3. Measurement scales and quality assessment scores.

\begin{tabular}{|c|c|c|c|c|}
\hline Author, year, journal, country & $\begin{array}{c}\text { Ethics } \\
\mathrm{Y} / \mathrm{N}\end{array}$ & Tools/Measures & $\begin{array}{l}\text { Reliability/ } \\
\text { Validity } \\
\text { Y/N }\end{array}$ & $\begin{array}{l}\text { Quality assessment } \\
\text { scores NH\&MRC/ } \\
\text { Polit \& Beck }\end{array}$ \\
\hline $\begin{array}{l}\text { Warren et al., 2016, Worldviews } \\
\text { on Evidence-based Nursing, } \\
\text { USA }\end{array}$ & $\mathrm{Y}$ & $\begin{array}{l}\text { The Evidence-Based Practice Beliefs Scale (EBPB), the } \\
\text { Evidence-Based Practice Implementation Scale (EBPI), } \\
\text { and the Organizational Culture and Readiness for } \\
\text { System-Wide Integration of EBP Scale (OCRSIEP) to } \\
\text { collect data. }\end{array}$ & $\mathrm{Y}$ & IV/VI \\
\hline
\end{tabular}

Kutney-Lee et al., 2015, Medical N Care, USA

Harris and Cohn, 2014, Nurse Leader, USA

Kaplan et al., 2014, Journal for Y Nurses in Professional Development, USA

Shepherd et al., 2014, Journal of N Nursing Education \&

Practice, USA
Practice Environment Scale of the Nursing Work Index (PES-NWI). 31 item includes 5 subscales: 1. Collegial nurse-physician relations, 2 . Nurse manager ability, 3. Nursing foundations for quality of care, 4 . Nurse participation in hospital affairs, \& 5. Staffing \& resource adequacy. Pennsylvania Registered Nurse Survey 1999 Multi-state Nursing Care \& Patient Safety Survey 2006. Patient outcomes. Nurse-reported quality outcomes. Nurse job outcomes.

Nursing strategic plan year end results 2012 included: National Database of Nursing Quality Indicators (NDNQI) database, Practice environment scale

Three scales were developed \& validated by the Advancing Research \& Clinical Practice Through Close Collaboration (MeInyk, Fineout-Overholt, Stillwell, \& Williamson, 2010). Organizational culture \& readiness for system-wide integration of EBP scale; the EBP beliefs scale; \& the EBP implementation scale.

Baseline survey developed from the shared governance literature - the questions were linked to shared governance concepts, perceived barriers, and staff's willingness to implement shared governance. Questions included: staff buy-in/ownership, structure for shared decision-making in place, knowledge of shared governance role, and knowledge of how to form a council. National database of nursing quality registered nurse survey. 
Urden et al., 2013, The Journal Y of Nursing Administration, USA

Hession-Laband and Mantell, 2011, Journal of Pediatric Nursing, USA

King, 2011, American Society of N Radiologic Technologists

Scanner, USA

Jost and Rich, 2010, Nursing Administration Quarterly, USA

Trinkoff et al., 2010, Journal of Y Nursing Administration, USA
An investigator-developed demographic information form (DIF) was used to collect the following information: age, number of years in current position, number of years in the organization, current employment status, facility, nursing degree, professional certification (national), unit, quality, and/or MAGNET committee involvement

12 question survey - to assess nurses' current practice about event reporting. Pilot tested on a small group of leadership nurses prior to distribution. Survey listed 34 specific events \& asked nurses to check the ones for which they would file a report. Areas of interest:

Understanding \& reporting behaviours regarding the

filing of safety events; surrounding near misses; potential barriers to the filing of safety events.

No tools or measures identified.

No tools or measures clearly identified.

Work Schedule Index: hours per day, hours per week, days per week, weekends per month, breaks of $10+$ minutes,

full- versus part-time, \& shift (days only v other). Job demands were measured by the Job Content

Questionnaire (JCQ), validated to measure the

psychosocial work environment of the organization

based on individual responses in multiple occupations

\& nurse samples. Nurse practice environment measures included autonomy, support, perceived patient safety culture, \& job satisfaction, with items from the Nursing Work Index-Revised (NWI-R). Patient Safety Center of Inquiry Culture Survey Hospital Survey on Patient

Safety Culture. The NWI-R items measured physiciannurse relationships. Job satisfaction was assessed using 1 Likert-type item, as such measures correlate highly with multiple-item measures.
IV/VI

Work Schedule Index $=$ Y Job
Practice Environment Scale $=\mathrm{Y}$ 


\begin{tabular}{ll}
\hline & Eth \\
Author, year, journal, country & $\mathrm{Y} / \mathrm{N}$ \\
\hline Lewis, 2009, Nurse Leader, USA & $\mathrm{N}$ \\
Newcomb et al., 2009, Southern & $\mathrm{Y}$ \\
Online Journal of Nursing \\
Research, USA
\end{tabular}

Gerhardt and VanKuiken, 2008, Y The Journal of Nursing Administration, USA

Lacey et al., 2007, The Journal of Y Nursing Administration, USA

Ulrich et al., 2007, The Journal Y of Nursing Administration, USA

Upenieks and Abelew, 2006, The Y Health Care Manager, USA

Capuano et al., 2005, Health Care Management Review, USA

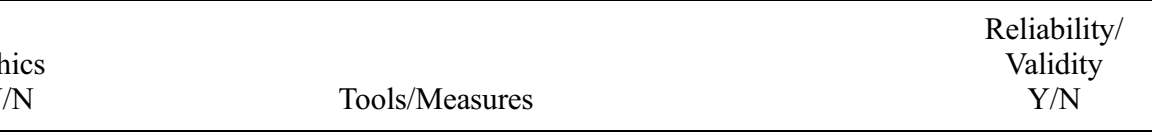

In-patient survey (2000-2008) Job satisfaction- NDNQI database

Nurse satisfaction measure - Index of Work Satisfaction (IWS), a global measure of overall satisfaction. Six subscales-pay, autonomy, task requirement, organizational policies, professional status, and interaction.

Barrier scale - 29 item 4 point Likert- type questionnaire. $Y$

The barrier items were categorised into 4 designated

Factors; factor 1 - characteristics of the adopter, factor 2 - characteristics of the organisation, factor 3 -

characteristics of the innovation, \& factor $4-$

characteristics of the communication. The remaining questions included 3 informational open-ended questions on other barriers, the greatest barriers to nurses' research utilisation \& what facilitates it.

Nursing Work Index - Revised Survey, (Aiken \& Patrician, 2000). 57-item questionnaire designed to measure organizational characteristics that were identified in Magnet hospitals.

Individual Workload Perception Scale (IWPS), a 32-item Y Likert scale survey. Subscales for the IWPS include manager, peer, unit support, workload, intent to stay, and nurse satisfaction.

No measurement scales described. Questionnaire not described.

Taped interviews using a guide from the MAGNET characteristics.

$\mathrm{N} \quad$ Leadership practices inventory scale. Work environment survey.
Quality assessment scores NH\&MRC Polit \& Beck

IV/VI

IV/VI 
Cimiotti et al., 2005, Nursing Research, USA

Force, 2004, The Health Care Manager, USA

Havens, 2001, Nursing Economics, USA

Aiken and Patrician, 2000, American Journal of Nursing, USA

Walker et al., 2014, The Journal N of Nursing Administration, Australia
Perceived Nurse Work Environment Scale (PNWE) - 42

items \& 9 demographic questions on a 1-4 Likert scale.

N Pre and post measurement surveys (audits of staff,

IV/VI

physicians, \& leaders). Press Ganey Satisfaction Survey score. Sperduto's Employee Satisfaction Survey.

National Database Collection. Professional Research

Consultants Survey. Turnover rates, employment

satisfaction, nurse morale, physician satisfaction \& inpatient satisfaction.

Seven-page questionnaire containing items re hospital characteristics, difficulty recruiting RNs, assessment of quality of care, organisation of the department of nursing, \& reports of degree of implementation of selected restructuring \& work redesign. Questionnaire Internal validity tested only. No external reliability reported. Organisational support scale - 10 item scale derived from NWI-R (Aiken \& Patrician, 2000). Degree of implementation of restructuring - a 9 item scale developed from Milton, Verran, Gerber, and Fleury (1995).

Y Nursing Work Index-Revised (NWI-R) - 49 item with a 4 Y

Scales $=\mathrm{Y}$

point Likert type scale. Gauges staff nurse perceptions of selected organisational traits in their work setting. Subscale constructs include: nurse autonomy, nurse control over the practice setting, and nurses' relations with physicians.

Practice environment scale modified version via online survey monkey. (PES-AUS) A 30 item scale with 5 subscales. 
Table 3. Continued.

\begin{tabular}{|c|c|c|c|c|}
\hline Author, year, journal, country & $\begin{array}{l}\text { Ethics } \\
\mathrm{Y} / \mathrm{N}\end{array}$ & Tools/Measures & $\begin{array}{l}\text { Reliability/ } \\
\text { Validity } \\
\text { Y/N }\end{array}$ & $\begin{array}{l}\text { Quality assessment } \\
\text { scores NH\&MRC/ } \\
\text { Polit \& Beck }\end{array}$ \\
\hline $\begin{array}{l}\text { Mäntynen et al., 2014, Nursing } \\
\text { Research \& Practice, Finland }\end{array}$ & Y & $\begin{array}{l}\text { A Transformational Leadership Scale. The Kuopio } \\
\text { University Hospital Job Satisfaction Scale (37 item }\end{array}$ & $\begin{array}{l}\text { Leadership Scale }=\text { Y Kuopio } \\
\text { University Hospital Job }\end{array}$ & IV/VI \\
\hline
\end{tabular}

divided into 7 subscales). Hospital Survey on Patient

Safety Culture (HSPSC) - developed and tested by the

Agency for Healthcare Research and Quality (AHRQ)

of the Department of Health and Human Services in the

United States. Revised Humane Caring Scale (RHCS).

The RHCS is a revised version of the Humane Caring

Scale-Developed measures the quality of care provided

by the staff of a hospital as a whole. Performance was

evaluated in a pilot test before its use in the main study.

George and Lovering, 2013,

$\mathrm{N}$ Joined the NDNQI in $2007 \mathrm{RN}$ satisfaction results

Satisfaction Scale $=$ Y

decision-making subscale. Nursing Turnover. Patient satisfaction scores.

Quarterly, Saudi Arabia

Balogh and Cook, 2006, Journal Y

Audio-taped private interviews lasted for 45 minutes on an

average. 23 face-to-face and 3 telephone interviews

from field notes of meetings attended by the researchers and from analysis of documents associated with the project.

Notes: OCRSIEP, Organizational Culture Readiness for System-wide Integration; EBPI, Evidence-based Practice Implementation; EBPB, Evidence-based Practice Belief; PES-NWI, Practice Environment Scale-Nurse Working Indicator; NDNQI, National Database of Nursing Quality Indicators; HCAHPS, Hospital Consumer Assessment of Healthcare Providers \& Systems; DIF, Demographic Information Form; ANCC, American Nurses Credentialing Center; USA, United States of America; NWI-R, Nursing Work Index Revised; IWPS, Individual Workload Perception Scale; LVHHN, Lehigh Valley Hospital \& Health Network; PE, Practice Environment; HSPSC, Hospital Survey on Patient Safety Culture; RHCS, Revised Humane Caring Scale; PNWE, Perceived Nurse Work Environment Scale; IWPS, Individual Workload Perception Scale; PES-AUS, practice. 
improved quality nursing practice, job satisfaction, and financial viability. Importantly, shared governance flattened hierarchal structures and promotes transformational leadership styles.

Transformational leadership is crucial to achieving nurse autonomy and creating the structures required to support the change. This style of leadership refers to the leader moving the follower beyond immediate self-interests through idealised influence (charisma), inspiration, intellectual stimulation, or individualised consideration (Bass, 1999). A recent study by van der Voet (2014) found that transformational leadership was dependent on the change approach that is 'planned or emergent' and the existing organisational structure within public organisations. Pragmatically, MAGNET, led by transformational leaders appeared to give nurses more autonomy in their roles and a greater contribution to governance of their work environment (Bamford \& PorterO'Grady, 2000). Leadership providing organisational support was crucial to achieving positive change at all levels within the organisation (Capuano et al., 2005; Kaplan et al., 2014; Mäntynen et al., 2014; Walker et al., 2014; Warren et al., 2016). In this integrative review, we identified the development of shared governance models was important in developing transformational leaders and these leaders were pivotal in developing a positive organisational culture.

Evidence around the role of MAGNET designation on culture would be enhanced by a shared definition of organisational culture and the use of common tools to explore components of organisational culture. We identified in this review that there are numerous tools used to measure organisational culture. We argue that multiplicity of tools/scales makes generalising problematic, as does the geographical and associated health contexts of the reviewed studies. The variability of measures used created difficulty comparing and contrasting across studies although the underlying concepts were often similar. Studies exploring organisational culture more widely, as distinct from MAGNET, suggest that organisational configuration is critical in attracting and retaining quality nurses by creating a positive working environment (Luzinski, 2011; Stordeur, D'Hoore, \& Group, 2007). MAGNET encapsulates a series of principles that can be applied independent of MAGNET verification to enhance working spaces (Doucette, 2012; Drake \& Berg, 2009; Hickey, Gauvreau, Tong, Schiffer, \& Connor, 2012). Perhaps MAGNET is critical in that it instigates an interactive cycle of culture shift, where preparation of MAGNET application induces changes that themselves impact on culture and this is repeated cyclically. Changes in organisations can continue to develop then as MAGNET designation processes continue to be implemented.

Undertaking MAGNET requires a substantial resource investment, combined with undertaking significant change processes - so it's important the benefits are clearly defined, measurable and achievable in multiple geographic, cultural and political contexts. Literature identifying MAGNET cost savings and patient care improvements in the Australian public system is limited, difficult to obtain and challenging to compare. Therefore, transferability to health care systems globally remains challenging. There are challenges and constraints translating north American values philosophies, structures, processes and outcomes embedded within MAGNET to the international arena. Educational mandates, clinical practices, staffing levels, costing models, and patient acuity may all be different in different international arenas. Therefore, it is important that the impact on MAGNET status is evaluated within a local context, using accepted, validated and appropriate tools.

\section{Limitations}

Due to the ambiguity of the term 'organisational culture', it is possible potential studies may have been missed using the identified search strategies. As the literature bridges across many disciplines and health care is a unique setting embedded within a socially economic environment, different approaches may be required. Although the search was not restricted based on year, 
the English language was a limiter. However, it is unlikely any studies were missed due to MAGNET's American background. Finally, it is difficult to develop clear recommendations based on studies that lack scientific rigour due to weaknesses in methodology, including ethical approvals and which used a wide range of measures collected primarily using non-validated tools.

\section{Directions for future research}

This review highlighted the need for research informed by sound methodology with clear and accepted definitions of cultural phenomena, organisational culture and underpinning theories. Moreover, longitudinal study designs will enable assessment of culture change over time and identification of interventions that promote such changes. The development of valid and reliable tools should be a priority area for future research. Partnering with external research experts is crucial to develop robust research processes to assess cultural change during and following MAGNET designation. Components of organisational culture can be both 'tangible and intangible', undertaking qualitative research processes will enable capture of the critical concepts for nurses.

\section{What is known about the topic?}

The MAGNET recognition program is recognised by healthcare providers as important in developing a positive organisational culture. This positive organisational culture improves patient outcomes and staff recruitment and retention.

\section{What does this paper add?}

An in depth integrative review exploring the impact of MAGNET designation on organisational culture has not been undertaken. In this paper, we have used an integrative review methodology to identify, examine, thematically group and critically evaluate published literature around the impact of MAGNET designation on organisational culture within designated hospitals.

\section{Implications for nursing and health policies}

The findings from this review support the MAGNET framework because of its positive impact on organisational culture for nurses. Transforming workplace culture is extremely challenging and requires significant financial and human resources to undertake and manage the change process. Nurse leaders and their leadership style are fundamental to engaging nurses in the transformational process. Although this review was specific to nursing, real change in health care requires an interdisciplinary approach and understanding this within the nursing context will promote success. It is essential therefore to engage teams with the critical skills required to lead and enact change within an evidence-based framework using a whole-system approach. Nurses need to address the deeper constructs of organisational culture in research to enable a clearer understanding of this complex topic prior to facilitating change.

\section{Conclusion}

Evidence presented in this review directs the conclusion that there is a positive and enhancing impact of MAGNET designation on organisational culture in the nursing context. Characteristics 
of the practice environment relevant to nurses such as nurse autonomy, nurse control, professional relationships and leadership were identified as key areas that positively influence workplace culture for nurses during development and upon designation of MAGNET status. Implementing a shared governance model was instrumental to creating a more positive environment that enhanced nurse autonomy. Using this framework proved beneficial even for hospitals that did not formally undergo MAGNET designation, although more high-quality research is required to support engagement with MAGNET by decision-makers who wish to explore this pathway to transforming culture in their organisation. Indeed, although this review indicates a positive link between MAGNET and workplace culture, the very essence of this transformation is unclear in the available literature.

\section{Acknowledgements}

We thank the MAGNET team at GCHHS for their enthusiasm and we also thank the library technician Sarah Thorning for undertaking the comprehensive database search.

\section{ORCID}

Vinah L. Anderson (D) http://orcid.org/0000-0001-9924-0159

Amy N.B. Johnston (iD http://orcid.org/0000-0002-9979-997X

\section{References}

Aiken, L. H., \& Patrician, P. A. (2000). Measuring organizational traits of hospitals: The revised nursing work index. Nursing Research, 49(3), 146-153.

Aiken, L. H., Smith, H. L., \& Lake, E. T. (1994). Lower Medicare mortality among a set of hospitals known for good nursing care. Medical Care, 32(8), 771-787.

Atkinson, M., Turkel, M., \& Cashy, J. (2008). Overcoming barriers to research in a magnet community hospital. Journal of Nursing Care Quality, 23(4), 362-368. doi:10.1097/01.NCQ.0000336675.48466.37. Retrieved from http://ovidsp.ovid.com/ovidweb.cgi?T $=\mathrm{JS} \& \mathrm{CSC}=\mathrm{Y} \& N E W S=\mathrm{N} \& \mathrm{PAGE}=$ fulltext\&D $=$ med5\&AN $=18806648$.

Balogh, R., \& Cook, M. (2006). Achieving magnet accreditation in the UK: A case study at Rochdale NHS trust. Journal of Nursing Management, 14(5), 366-376. Retrieved from http://ovidsp.ovid.com/ ovidweb.cgi? $\mathrm{T}=\mathrm{JS} \& \mathrm{CSC}=\mathrm{Y} \& \mathrm{NEWS}=\mathrm{N} \& \mathrm{PAGE}=$ fulltext $\& \mathrm{D}=$ med5\&AN $=16787471$.

Bamford, A., \& Porter-O'Grady, T. (2000). Shared governance within the market-oriented health care system of New Zealand. International Nursing Review, 47(2), 83-88.

Bashaw, E. S. (2011). Fusing Magnet ${ }^{\circledR}$ and just culture. American Nurse Today, 6(9), 42-45. 44p. Retrieved from http://search.ebscohost.com/login.aspx?direct=true\&AuthType=ip,athens\&db=ccm\&AN=10469 4859\&site $=$ ehost-live.

Basheaw, E. S., Rosenstein, A. H., \& Lounsbury, K. (2012). Culture trifecta: Building the infrastructure for Magnet ${ }^{\circledR}$ and just culture. American Nurse Today, 7(9), 36. 38-41 32p. Retrieved from http://search. ebscohost.com/login.aspx?direct=true\&AuthType=ip, athens\&db=ccm\&AN=108097169\&site=ehost-live

Bass, B. M. (1999). Two decades of research and development in transformational leadership. European Journal of Work and Organizational Psychology, 8(1), 9-32.

Brady-Schwartz, D. C. (2005). Further evidence on the magnet recognition program: Implications for nursing leaders. [Comparative Study]. Journal of Nursing Administration, 35(9), 397-403. Retrieved from http://ovidsp.ovid.com/ovidweb.cgi? $\mathrm{T}=\mathrm{JS} \& \mathrm{CSC}=\mathrm{Y} \& \mathrm{NEWS}=\mathrm{N} \& \mathrm{PAGE}=$ fulltext\&D $=$ med5 $\& \mathrm{AN}=16200007$

Broom, C., \& Tilbury, M. S. (2007). Magnet status. Journal of Nursing Care Quality, 22(2), 113-118. Retrieved from http://ovidsp.ovid.com/ovidweb.cgi?T $=\mathrm{JS} \& \mathrm{CSC}=\mathrm{Y} \& N E W S=\mathrm{N} \& \mathrm{PAGE}=$ fulltext\&D $=$ med5\&AN $=17353746$

Capuano, T., Bokovoy, J., Hitchings, K., \& Houser, J. (2005). Use of a validated model to evaluate the impact of the work environment on outcomes at a magnet hospital. Health Care Management 
Review, 30(3), 229-236. Retrieved from http://ovidsp.ovid.com/ovidweb.cgi?T $=$ JS\&CSC $=$ Y\&NEWS $=$ N\&PAGE $=$ fulltext $\& D=\operatorname{med} 5 \& A N=16093889$

Cimiotti, J. P., Quinlan, P. M., Larson, E. L., Pastor, D. K., Lin, S. X., \& Stone, P. W. (2005). The magnet process and the perceived work environment of nurses. Nursing Research, 54(6), 384-390. Retrieved from http://ovidsp.ovid.com/ovidweb.cgi? T $=\mathrm{JS} \& \mathrm{CSC}=\mathrm{Y} \& \mathrm{NEWS}=\mathrm{N} \& \mathrm{PAGE}=$ fulltext\&D $=$ med5 $\& A N=16317359$

Doucette, J. N. (2012). Aligning systems with the magnet ${ }^{\circledR}$ model to create a culture of safety. Nursing Management (Springhouse), 43(7), 52-55. doi:10.1097/01.NUMA.0000415501.60482.6b. Retrieved from http://ovidsp.ovid.com/ovidweb.cgi? $\mathrm{T}=\mathrm{JS} \& \mathrm{CSC}=\mathrm{Y} \& \mathrm{NEWS}=\mathrm{N} \& \mathrm{PAGE}=$ fulltext\&D $=$ medl $\& \mathrm{AN}=22733056$

Drake, E., \& Berg, R. (2009). A hospital's journey toward a professional development program. Newborn \& Infant Nursing Reviews, 9(2), 91-98. Retrieved from http://search.ebscohost.com/login.aspx?direct= true \&AuthType $=i p$,athens $\& d b=c c m \& A N=105358969 \&$ site $=$ ehost-live

Drenkard, K. (2011). Magnet momentum: Creating a culture of safety. Nurse Leader, 9(4), 28-46. 19p. doi:10.1016/j.mnl.2011.05.013 Retrieved from http://search.ebscohost.com/login.aspx?direct= true \&AuthType $=$ ip, athen $\& d b=c c m \& A N=104669247 \&$ site $=$ ehost-live

Drenkard, K. N. (2005). Sustaining magnet. Nursing Administration Quarterly, 29(3), 214-222. Retrieved from http://ovidsp.ovid.com/ovidweb.cgi?T $=\mathrm{JS} \& C S C=$ Y \&NEWS $=$ N\&PAGE $=$ fulltext $\& D=$ med5 $\& \mathrm{AN}=16056155$

Force, M. V. (2004). Creating a culture of service excellence. The Health Care Manager, 23(3), 262-266. Retrieved from http://search.ebscohost.com/login.aspx?direct=true\&AuthType=ip, athens\&db=ccm\& $\mathrm{AN}=106555595 \&$ site $=$ ehost-live

George, V., \& Lovering, S. (2013). Transforming the context of care through shared leadership and partnership. Nursing Administration Quarterly, 37(1), 52-59. doi:10.1097/NAQ.0b013e3182751732. Retrieved from http://ovidsp.ovid.com/ovidweb.cgi?T $=\mathrm{JS} \& C S C=$ Y\&NEWS $=$ N\&PAGE $=$ fulltext\& $\mathrm{D}=$ medl\&AN $=23222754$

Gerhardt, W. E., \& VanKuiken, D. (2008). Assessing magnet readiness using the nursing work index-revised survey. JONA: The Journal of Nursing Administration, 38(10), 429-434. doi:10.1097/01.NNA. 0000338151.79858.ea. Retrieved from http://ovidsp.ovid.com/ovidweb.cgi?T $=$ JS\&CSC $=$ Y\&NEWS $=\mathrm{N} \& \mathrm{PAGE}=$ fulltext $\& \mathrm{D}=$ med $5 \& \mathrm{AN}=18849747$

Gold Coast Health. (2016). Gold Coast Health Strategic Plan 2016-2020. http://gchweb.sth.health.qld.gov. au/documents/PLA1443

Harris, D., \& Cohn, T. (2014). Designing and opening a new hospital with a culture and foundation of Magnet ${ }^{\circledR}:$ An exemplar in transformational leadership. Nurse Leader, 12(4), 62-77. doi:10.1016/j. $\mathrm{mnl} .2013 .10 .002$. Retrieved from http://search.ebscohost.com/login.aspx?direct=true\&AuthType=ip, athens \&db=ccm\&AN=103984434\&site=ehost-live

Havens, D. S. (2001). Comparing nursing infrastructure and outcomes: ANCC magnet and nonmagnet CNEs report. Chief Nurse Executives. Nursing Economics, 19(6), 258-266. Retrieved from http://search. ebscohost.com/login.aspx?direct=true\&AuthType $=$ ip, athen $\& \mathrm{db}=\mathrm{ccm} \& A N=106903890 \&$ site $=$ ehost-live

Hess, R., Desroches, C., Donelan, K., Norman, L., \& Buerhaus, P. I. (2011). Perceptions of nurses in magnet ${ }^{\circledR}$ hospitals, Non-magnet hospitals, and hospitals pursuing magnet status. JONA: The Journal of Nursing Administration, 41(7-8), 315-323. doi:10.1097/NNA.0b013e31822509e2. Retrieved from http://ovidsp.ovid.com/ovidweb.cgi?T $=$ JS\&CSC $=$ Y\&NEWS $=$ N\&PAGE $=$ fulltext\&D $=$ med5\&AN $=21799363$

Hession-Laband, E., \& Mantell, P. (2011). Lessons learned: Use of event reporting by nurses to improve patient safety and quality. Journal of Pediatric Nursing, 26(2), 149-155. doi:10.1016/j.pedn.2010.12. 005. Retrieved from http://ovidsp.ovid.com/ovidweb.cgi? $=\mathrm{JS} \& \mathrm{CSC}=\mathrm{Y} \& \mathrm{NEWS}=\mathrm{N} \& \mathrm{PAGE}=$ fulltext\&D $=$ med5\&AN $=21419975$

Hickey, P. A., Gauvreau, K., Tong, E., Schiffer, N. P., \& Connor, J. A. (2012). Pediatric cardiovascular critical care in the United States: Nursing and organizational characteristics. American Journal of Critical Care, 21(4), 242-250. doi:10.4037/ajcc2012853. Retrieved from http://search.ebscohost.com/login. aspx?direct $=$ true \&AuthType $=\mathrm{ip}$, athens $\& \mathrm{db}=\mathrm{ccm} \& \mathrm{AN}=104473315 \&$ site $=$ ehost-live

Jost, S. G., \& Rich, V. L. (2010). Transformation of a nursing culture through actualization of a nursing professional practice model. Nursing Administration Quarterly, 34(1), 30-40. doi:10.1097/NAQ. 0b013e3181c95ee8. Retrieved from http://ovidsp.ovid.com/ovidweb.cgi? T $=$ JS\&CSC $=$ Y\&NEWS $=$ $\mathrm{N} \& \mathrm{PAGE}=$ fulltext $\& \mathrm{D}=$ med5 $\& \mathrm{AN}=20023559$

Kaplan, L., Zeller, E., Damitio, D., Culbert, S., \& Bayley, K. B. (2014). Improving the culture of evidencebased practice at a magnet ${ }^{\circledR}$ hospital. Journal for Nurses in Professional Development, 30(6), 274-280. 
quiz E271-272. doi:10.1097/NND.0000000000000089. Retrieved from http:/ovidsp.ovid.com/ ovidweb.cgi? $\mathrm{T}=\mathrm{JS} \& \mathrm{CSC}=\mathrm{Y} \& \mathrm{NEWS}=\mathrm{N} \& \mathrm{PAGE}=$ fulltext $\& \mathrm{D}=$ medl\&AN $=25407970$

King, T. (2011). Magnet status. ASRT Scanner, 43(3), 26-30. Retrieved from http://search.ebscohost.com/ login.aspx?direct $=$ true \&AuthType $=$ ip, athen $\& d b=c c m \& A N=104815499 \&$ site $=$ ehost-live

Kutney-Lee, A., Stimpfel, A. W., Sloane, D. M., \& Cimiotti, J. P. (2015). Changes in patient and nurse outcomes associated with magnet hospital recognition. Medical Care, 53(6), 550-557.

Lacey, S. R., Cox, K. S., Lorfing, K. C., Teasley, S. L., Carroll, C. A., \& Sexton, K. (2007). Nursing support, workload, and intent to stay in Magnet. Magnet-aspiring, and non-Magnet Hospitals. [Comparative Study]. Journal of Nursing Administration, 37(4), 199-205. Retrieved from http://ovidsp.ovid.com/ ovidweb.cgi? $=\mathrm{JS} \& \mathrm{CSC}=\mathrm{Y} \& \mathrm{NEWS}=\mathrm{N} \& \mathrm{PAGE}=$ fulltext $\& \mathrm{D}=\operatorname{med} 5 \& \mathrm{AN}=17415107$

Lewis, L. C. (2009). Mission critical: Building a culture of excellence. Nurse Leader, 7(2), 20-24. Retrieved from http://search.ebscohost.com/login.aspx?direct=true\&AuthType=ip,athens $\& \mathrm{db}=\mathrm{ccm} \& \mathrm{AN}=$ 105515620\&site $=$ ehost-live

Luzinski, C. (2011). Introducing the official leadership journal of the magnet recognition program ${ }^{\circledR}$. JONA: The Journal of Nursing Administration, 41(10), 389-390. doi:10.1097/NNA.0b013e31822edb79. Retrieved from http://ovidsp.ovid.com/ovidweb.cgi?T $=$ JS\&CSC $=$ Y\&NEWS $=$ N\&PAGE $=$ fulltext\&D $=$ med5\&AN $=21934422$

Mannion, R., Davies, H. T., \& Marshall, M. N. (2005). Cultural characteristics of "high" and "low" performing hospitals. Journal of Health Organization and Management, 19(6), 431-439. doi:10.1108/ 14777260510629689. Retrieved from http://www.ncbi.nlm.nih.gov/pubmed/16375066

Mäntynen, R., Vehviläinen-Julkunen, K., Partanen, P., Turunen, H., Miettinen, M., \& Kvist, T. (2014). Changes in transformational leadership and empirical quality outcomes in a Finnish hospital over a two-year period: A longitudinal study. Nursing Research and Practice, 1-9. doi:10.1155/2014/ 218069. Retrieved from http://www.ncbi.nlm.nih.gov/pmc/articles/PMC4070428/

MeInyk, B.M., Fineout-Overholt, E., Stillwell, S.B., \& Williamson, K.M. (2010). Evidence-based practice: Step by step: The seven steps of evidence-based practice. The American Journal of Nursing, 110(1), 5153. doi:10.1097/01.NAJ.0000366056.06605.d2

Miles, M. B., \& Huberman, A. M. (1994). Qualitative data analysis. Thousand Oaks, CA: Sage.

Milton, D.A., Verran, J.A., Gerber, R.M., \& Fleury, J. (1995). Tools to evaluate reengineering progress. In S. Blanchett, \& D. Flahey (Eds.), The handbook for organizational transformation (pp. 195-202). Gaithersburg, MD: Aspen Publications.

Moher, D., Liberati, A., Tetzlaff, J., Altman, D. G., \& Group, P. (2010). Preferred reporting items for systematic reviews and meta-analyses: The PRISMA statement. International Journal of Surgery, 8(5), 336-341. doi:10.1016/j.ijsu.2010.02.007. Retrieved from http:/www.ncbi.nlm.nih.gov/pubmed/ 20171303

National Health and Medical Research Council. (2009). NHMRC additional levels of evidence and grades for recommendations for developers of guidelines. Retrieved Date Accessed, 2016 from https://www. nhmrc.gov.au/_files_nhmrc/file/guidelines/developers/nhmrc_levels_grades_evidence_120423.pdf

Newcomb, P., Smith, A., \& Webb, P. (2009). Relationship of nurse job satisfaction to implementation of a nursing professional practice model. Southern Online Journal of Nursing Research, 9(3), 6-6. Retrieved from http://search.ebscohost.com/login.aspx?direct=true\&AuthType=ip, athens\&db=ccm\&AN=1054 $19868 \&$ site $=$ ehost-live

Petit Dit Dariel, O., \& Regnaux, J. P. (2015, p. 198). Do magnet ${ }^{\circledR}$-accredited hospitals show improvements in nurse and patient outcomes compared to non-magnet hospitals: A systematic review. The JBI Database of Systematic Reviews and Implementation Reports, 13(6), 168-219. doi:10.11124/jbisrir2015-2262. Retrieved from http://ovidsp.ovid.com/ovidweb.cgi? $\mathrm{T}=\mathrm{JS} \& \mathrm{CSC}=\mathrm{Y} \& \mathrm{NEWS}=\mathrm{N} \&$ PAGE $=$ fulltext $\& D=$ prem $\& A N=26455752$

Polit-O'Hara, D., \& Beck, C. T. (2006). Essentials of nursing research: Methods, appraisal, and utilization (6th ed.). Philadelphia, PA: Lippincott Williams \& Wilkins.

Porter-O'Grady, T. (1991). Shared governance for nursing. AORN Journal, 53(2), 458-467.

Salmond, S. W., Begley, R., Brennan, J., \& Saimbert, M. K. (2009). A comprehensive systematic review of evidence on determining the impact of Magnet designation on nursing and patient outcomes: Is the investment worth it? The JBI Database of Sytematic Reviews and Implementation Reports, 7(26), $1119-1178$.

Schmalenberg, C., \& Kramer, M. (2007). Types of intensive care units with the healthiest, most productive work environments. American Journal of Critical Care, 16(5), 458-468. quiz 469. Retrieved from http:// www.embase.com/search/results?subaction $=$ viewrecord \&from $=$ export\&id $=$ L350310830 
Scott, J. G., Sochalski, J., \& Aiken, L. H. (1999). Review of magnet hospital research. JONA: The Journal of Nursing Administration, 29(1), 9-19.

Shepherd, M. L., Harris, M. L., Chung, H., \& Himes, E. M. (2014). Using the awareness, desire, knowledge, ability. Reinforcement Model to Build a Shared Governance Culture. Journal of Nursing Education \& Practice, 4(6), 90-104. doi:10.5430/jnep.v4n6p90. Retrieved from http://search.ebscohost.com/login. aspx? direct $=$ true $\&$ AuthType $=$ ip, athens $\& \mathrm{db}=\mathrm{ccm} \& A N=109229117 \&$ site $=$ ehost-live

Stone, P. W., Mooney-Kane, C., Larson, E. L., Horan, T., Glance, L. G., Zwanziger, J., \& Dick, A. W. (2007). Nurse working conditions and patient safety outcomes. Medical Care, 45(6), 571-578. Retrieved from http://ovidsp.ovid.com/ovidweb.cgi? $\mathrm{T}=\mathrm{JS} \& \mathrm{CSC}=\mathrm{Y} \& \mathrm{NEWS}=\mathrm{N} \& \mathrm{PAGE}=$ fulltext\&D $=$ med5\&AN $=17515785$

Stordeur, S., D'Hoore, W., \& Group, N. E.-S. (2007). Organizational configuration of hospitals succeeding in attracting and retaining nurses. Journal of Advanced Nursing, 57(1), 45-58. Retrieved from $\mathrm{http}$ //ovidsp.ovid.com/ovidweb.cgi?T $=\mathrm{JS} \& \mathrm{CSC}=\mathrm{Y} \& \mathrm{NEWS}=\mathrm{N} \& \mathrm{PAGE}=$ fulltext $\& \mathrm{D}=$ med5\&AN $=17184373$.

Tozer, J. (1999). Leading initiatives: Leadership, teamwork and the bottom line. Port Melbourne: Butterworth-Heinemann.

Trinkoff, A. M., Johantgen, M., Storr, C. L., Han, K., Liang, Y., Gurses, A. P., \& Hopkinson, S. (2010). A comparison of working conditions among nurses in magnet ${ }^{\circledR}$ and non-magnet ${ }^{\circledR}$ hospitals. JONA: The Journal of Nursing Administration, 40(7-8), 309-315. doi:10.1097/NNA.0b013e3181e93719. Retrieved from http://ovidsp.ovid.com/ovidweb.cgi?T $=\mathrm{JS} \& \mathrm{CSC}=\mathrm{Y} \& \mathrm{NEWS}=\mathrm{N} \& \mathrm{PAGE}=$ fulltext\&D $=$ med5\&AN $=20661060$

Ulrich, B. T., Buerhaus, P. I., Donelan, K., Norman, L., \& Dittus, R. (2007). Magnet status and registered nurse views of the work environment and nursing as a career [Reprint in J Nurs Adm. 2009 JulAug;39(7-8 Suppl):S54-62; PMID: 19641440]. [Research Support, Non-U.S. Gov't]. Journal of Nursing Administration, 37(5), pp. 212-220. Retrieved from http://ovidsp.ovid.com/ovidweb.cgi?T = $\mathrm{JS} \& \mathrm{CSC}=\mathrm{Y} \& \mathrm{NEWS}=\mathrm{N} \& \mathrm{PAGE}=$ fulltext $\& \mathrm{D}=\operatorname{med} 5 \& \mathrm{AN}=17479039$

Upenieks, V. V., \& Abelew, S. (2006). The magnet designation process. The Health Care Manager, 25(3), 243-253. Retrieved from http://ovidsp.ovid.com/ovidweb.cgi?T $=\mathrm{JS} \& \mathrm{CSC}=\mathrm{Y} \& \mathrm{NEWS}=\mathrm{N} \& \mathrm{PAGE}=$ fulltext\&D $=$ med5\&AN $=16905996$

Urden, L. D., Ecoff, L. K., Baclig, J., \& Gerber, C. S. (2013). Staff nurse perceptions of the magnet ${ }^{\circledR}$ journey. JONA: The Journal of Nursing Administration, 43(7-8), 403-408. doi:10.1097/NNA. 0b013e31829d61aa. Retrieved from http://ovidsp.ovid.com/ovidweb.cgi? $\mathrm{T}=\mathrm{JS} \& \mathrm{CSC}=\mathrm{Y} \& \mathrm{NEWS}=$ $\mathrm{N} \& \mathrm{PAGE}=$ fulltext $\& \mathrm{D}=$ medl $\& A N=23892305$

van der Voet, J. (2014). The effectiveness and specificity of change management in a public organization: Transformational leadership and a bureaucratic organizational structure. European Management Journal, 32(3), 373-382. doi:10.1016/j.emj.2013.10.001. Retrieved from http://www.sciencedirect. com/science/article/pii/S0263237313001175

Walker, K., Fitzgerald, K., \& Duff, J. (2014). Supporting a healthy culture. JONA: The Journal of Nursing Administration, 44(12), 653-658. doi:10.1097/NNA.0000000000000143. Retrieved from http://ovidsp. ovid.com/ovidweb.cgi? $=\mathrm{JS} \& C S C=$ Y\&NEWS $=$ N\&PAGE $=$ fulltext $\& D=$ medl\&AN $=25393142$.

Warren, J. I., McLaughlin, M., Bardsley, J., Eich, J., Esche, C. A., Kropkowski, L., \& Risch, S. (2016). The strengths and challenges of implementing EBP in healthcare systems. Worldviews on Evidence-Based Nursing, 13(1), 15-24. doi:10.1111/wvn.12149. Retrieved from http:/ovidsp.ovid.com/ovidweb.cgi? $\mathrm{T}=\mathrm{JS} \& \mathrm{CSC}=\mathrm{Y} \& \mathrm{NEWS}=\mathrm{N} \& \mathrm{PAGE}=$ fulltext $\& \mathrm{D}=$ prem $\& A N=26873372$

Whittemore, R., \& Knafl, K. (2005). The integrative review: Updated methodology. Journal of Advanced Nursing, 52(5), 546-553. doi:10.1111/j.1365-2648.2005.03621.x. Retrieved from http://www.ncbi. nlm.nih.gov/pubmed/16268861

Wooten, L. P., \& Crane, P. (2003). Nurses as implementers of organizational culture. Nursing Economics, 21 (6), 275-279. Retrieved from http://go.galegroup.com.libraryproxy.griffith.edu.au/ps/i.do?id=GALE\% 7CA111733708\&v=2.1\&u=griffith\&it=r\&p=HRCA\&sw=w\&asid=3435e18af00554c92328cfd131f88e7b 
(1)

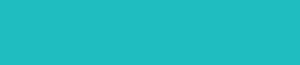

\title{
Impact of MAGNET hospital designation on nursing culture: an integrative review
}

\author{
Vinah L. Anderson, Amy N.B. Johnston, Debbie Massey \& Anita Bamford- \\ Wade
}

To cite this article: Vinah L. Anderson, Amy N.B. Johnston, Debbie Massey \& Anita BamfordWade (2018): Impact of MAGNET hospital designation on nursing culture: an integrative review, Contemporary Nurse, DOI: 10.1080/10376178.2018.1507677

To link to this article: https://doi.org/10.1080/10376178.2018.1507677

册 Published online: 09 Aug 2018.

Submit your article to this journal $\widetilde{ }$

View Crossmark data 